\title{
Predictors of glycemic control among patients with Type 2 diabetes: A longitudinal study
} Stephen R Benoit*1, Regina Fleming ${ }^{1}$, Athena Philis-Tsimikas ${ }^{2}$ and Ming Ji ${ }^{3}$

Address: ${ }^{1}$ University of California, San Diego - San Diego State University Preventive Medicine Residency, Dept. of Family and Preventive Medicine, MC-0811, 9500 Gilman Drive, La Jolla, CA 92093-0811, USA, 2The Whittier Institute for Diabetes, Scripps Health, 9894 Genesee Ave., La Jolla, CA 92037, USA and 3San Diego State Graduate School of Public Health, 5500 Campanile Drive, San Diego, CA 92182-4162, USA

Email: Stephen R Benoit* - bvy8@cdc.gov; Regina Fleming - GMagit1022@aol.com; Athena Philis-Tsimikas - Philis-

Tsimikas.Athena@scrippshealth.org; Ming Ji-mji@mail.sdsu.edu

* Corresponding author

Published: 17 April 2005

BMC Public Health 2005, 5:36 doi:10.1 186/147|-2458-5-36

This article is available from: http://www.biomedcentral.com/I47I-2458/5/36

(C) 2005 Benoit et al; licensee BioMed Central Ltd.

This is an Open Access article distributed under the terms of the Creative Commons Attribution License (http://creativecommons.org/licenses/by/2.0), which permits unrestricted use, distribution, and reproduction in any medium, provided the original work is properly cited.
Received: 25 October 2004

Accepted: 17 April 2005

\begin{abstract}
Background: Diabetes is the sixth leading cause of death and results in significant morbidity. The purpose of this study is to determine what demographic, health status, treatment, access/quality of care, and behavioral factors are associated with poor glycemic control in a Type 2 diabetic, lowincome, minority, San Diego population.
\end{abstract}

Methods: Longitudinal observational data was collected on patients with Type 2 diabetes from Project Dulce, a program in San Diego County designed to care for an underserved diabetic population. The study sample included 573 patients with a racial/ethnic mix of $53 \%$ Hispanic, $7 \%$ black, $18 \%$ Asian, $20 \%$ white, and $2 \%$ other. We utilized mixed effects models to determine the factors associated with poor glycemic control using hemoglobin AIC (AIC) as the outcome of interest. A multi-step model building process was used resulting in a final parsimonious model with main effects and interaction terms.

Results: Patients had a mean age of 55 years, $69 \%$ were female, the mean duration of diabetes was 7.1 years, $31 \%$ were treated with insulin, and $57 \%$ were obese. American Diabetes Association (ADA) recommendations for blood pressure and total cholesterol were met by $71 \%$ and $68 \%$, respectively. Results of the mixed effects model showed that patients who were uninsured, had diabetes for a longer period of time, used insulin or multiple oral agents, or had high cholesterol had higher AIC values over time indicating poorer glycemic control. The younger subjects also had poorer control.

Conclusion: This study provides factors that predict glycemic control in a specific low-income, multiethnic, Type 2 diabetic population. With this information, subgroups with high risk of disease morbidity were identified. Barriers that prevent these patients from meeting their goals must be explored to improve health outcomes.

\section{Background}

Approximately 13 million people have been diagnosed with diabetes in the United States and an additional 5.2 million do not yet know they have the disease [1]. Of these people, $90-95 \%$ have Type 2 diabetes [2]. Diabetes has been among the top ten leading causes of death in the 
United States since 1932 and is now the sixth leading cause of death [3]. Because of the magnitude of the burden of disease, the Healthy People 2010 objectives include goals of reducing diabetes-related deaths and increasing the monitoring frequency of glucose control and chronic complications [4]. The United Kingdom Prospective Diabetes Study and Kumamoto study confirm that improved glucose control reduces the microvascular complications in Type 2 diabetes such as retinopathy, nephropathy, and neuropathy $[5,6]$. Because of these findings, new standards of care and new models of health care delivery have emerged [7].

Disease management programs that incorporate group patient education, nutrition consultation, case management as well as close clinical care have been effective [8]. Project Dulce, an initiative of Community Health Improvement Partners, the Council of Community Clinics, and The Whittier Institute for Diabetes was started in 1998 in San Diego County. The program has a multifaceted approach and focuses on providing care to minority groups that often lack access to medical services.

Although it is known that improved glycemic control improves microvascular outcomes, less is known about the factors that influence control. Harris et al. [9] examined racial and ethnic differences in glycemic control in patients with Type 2 diabetes using the Third National Health and Nutrition Examination Survey (NHANES III) and found that black women, Mexican-American men, those treated with insulin or oral antiglycemic medications, and patients over 60 years of age had poorer glycemic control. Shorr et al. [10] studied the relationship between age and glycemic control and found no significant differences between age groups. Nichols et al. [11] found that age, body mass index (BMI) and emotional distress were significantly related to glycemic control in a health maintenance organization population in Oregon. Blaum et al. [12] found that disease duration, C peptide levels, poor self-care, and failure to receive diet recommendations were related to control in a mostly white, primary care population in Michigan. Project Dulce, however, is a distinct population of low-income, multiethnic patients with a high proportion of Hispanics and Asians. Therefore, it is useful to study patient characteristics associated with glycemic control in this unique setting. Prior studies have not accounted for fluctuations in glycemic control over time. We used a longitudinal data analysis approach to account for glycemic variation and thus maximized the amount of information that can be drawn from the data.

\section{Methods \\ Data study sample}

Project Dulce is a nurse-based diabetes disease management system in San Diego, California [13]. Patients with diabetes are referred to Project Dulce by primary care providers. Once the patient is referred, the nurse educator conducts an initial assessment and follows the American Diabetes Association (ADA) standards of appropriate physical and laboratory exams and referrals to specialists (7). Hemoglobin A1C (A1C) is monitored quarterly and lipids, urine microalbumin, thyroid stimulating hormone (TSH), and retinal exams are completed yearly or more frequently as needed. At each visit, height, weight, blood pressure, foot exams, and glucometer results are reviewed.

The nurse educator is the case manager and follows-up on missed patient appointments and identifies individual service and access needs of his/her panel of patients. The nurse also communicates with the primary care physician regarding clinical care issues. Project Dulce Dieticians see patients referred by the nurse educators. The program is active in seventeen sites including community clinics and hospital ambulatory care centers throughout San Diego County. Project Dulce uses the same procedures and supervision at each site and tracks patients with the Diabetes Electronic Management System (DEMS) software. The database contains demographic, health status, treatment, laboratory, and behavioral factors for each patient and collects the information over time. This study included data from July 18, 2000 to October 7, 2002 and was approved by the Institutional Review Board of San Diego State University.

\section{Eligibility criteria}

For purposes of this analysis, we selected patients with Type 2 diabetes, reducing the population size from 1,728 to 1,357 . To avoid bias and ensure that the study population was actively participating in the Project Dulce program, inclusion criteria were established. The patient required: 1) at least two A1C values at least six months apart, 2) participation in the program for at least six months, and 3) at least three Project Dulce provider visits. Of the 1,357 Type 2 diabetes patients in the database, 573 met these criteria.

\section{Measures}

\section{a. Demographics}

Demographic variables included gender, age, race/ethnicity, and primary language. All were of low socioeconomic status. For purposes of this study, five racial/ethnic categories were created: Hispanic, Asian (including Indian), black, white, and other. 


\section{b. Glycemic control}

$\mathrm{A} 1 \mathrm{C}$ is a laboratory value that indicates glycemic control over a 2 to 3 month period; values less than $7 \%$ are considered optimal. A1C was our outcome of interest and was evaluated over time by examining the patients' A1C laboratory results over a 24 month period. Since Project Dulce follows the ADA recommendations of checking A1C values every 3 months, values were placed in 3 month block intervals, using the patients' initial provider visit as the reference starting point. A1C laboratory data on individual patients was not always precisely three months apart so approximations were necessary. Since A1C is an indicator of glycemic control over a 2 to 3 month period, we used a plus or minus 1.5 month approximation. For example, a three-month lab was considered an A1C measurement 1.5 to 4.5 months after the initial Project Dulce visit. A baseline $\mathrm{A} 1 \mathrm{C}$ value was considered a measurement between 2.8 months before the initial Project Dulce visit to 1.5 months after the visit. Since a two year time period was of interest in this study, only A1C values falling within 2.8 months of the initial visit or 25.5 months after this visit were included in the analysis. If more than one $\mathrm{A} 1 \mathrm{C}$ value was available in a particular 3 month time block, the first measurement within that block was used.

\section{c. Diabetes severity}

The difference in dates of the patient's initial Project Dulce visit and the diabetes diagnosis date estimated disease duration in years. Medicines used for glucose control (insulin, sulfonylureas, metformin, glitazones, alpha glucosidase inhibitors, meglitinides) were categorized into three levels: 1) insulin alone or insulin with oral agents, 2) more than one oral agent but no insulin, and 3) one oral medication or no medication at all. Since a patient's pharmacotherapy changed over time, we created a coding strategy. If the patient used insulin at any point over the two year study period, he/she was placed in the insulin category. Similarly, if the patient ever used more than one oral medication but never used insulin, the patient was placed in the more than one oral agent category.

\section{d. Health status}

Clinical characteristics considered included systolic (SBP) and diastolic (DBP) blood pressure, total and HDL cholesterol, urine microalbumin-to-creatinine ratio, and BMI. Mean values of the clinical variables were used over the appropriate time period. In univariate analysis, cutpoints were created based on ADA guidelines [7]. Hypertension was considered SBP or DBP greater than or equal to 130 $\mathrm{mm} \mathrm{Hg}$ and $80 \mathrm{~mm} \mathrm{Hg}$, respectively. Total cholesterol or HDL greater than equal to $200 \mathrm{mg} / \mathrm{dl}$ and $45 \mathrm{mg} / \mathrm{dl}$, respectively were defined as dyslipidemia. Urine microalbumin-to-creatinine levels between 30 and $299 \mathrm{ug} / \mathrm{mg}$ was considered microalbuminuria and greater than or equal to $300 \mathrm{ug} / \mathrm{mg}$ was considered clinical albuminuria.
BMI greater than or equal to $30 \mathrm{~kg} / \mathrm{m}^{2}$ was considered obese.

\section{e. Access / quality of care}

Most of the patients in Project Dulce have County Medical Services, an insurance program funded by San Diego County to care for the medically indigent adult population (MIA). The remainder are uninsured and pay out-ofpocket to enroll in the program or are covered by Medicare, Medicaid, or private insurance. For purposes of this study insurance status was categorized as uninsured, MIA, or insured (insured = Medicare, Medicaid or private insurance). The number of provider visits, duration in the program, and whether the patient was seen by a Project Dulce nutritionist was also recorded.

\section{f. Behavioral factors}

Behavioral factors in the model included smoking and the number of Project Dulce diabetes education classes attended.

\section{Descriptive and Univariate analysis}

The number and proportion of patients were recorded for each variable within demographic, diabetes severity, health status, access/quality of care, and behavioral factor groups. In addition, mean $\mathrm{A} 1 \mathrm{C}$ values were compared across levels of each variable. Univariate analysis using a t-test or One-Way ANOVA was used to assess significant differences in mean A1C. If significant differences were found in ANOVA, the Duncan function in SAS 8.1 was used to asses individual differences.

\section{Mixed effects model}

Mixed effects models were used to assess glycemic control by analyzing the repeated measure data of $\mathrm{A} 1 \mathrm{C}$ values. The $\mathrm{A} 1 \mathrm{C}$ values were skewed and therefore log transformed in order to meet the normal distribution assumption. Several correlation structures including Compound Symmetry, Unstructured, First-order Autoregressive, and Toeplitz were assessed for each model. We used Akaike's Information Criterion (AIC) to select the appropriate correlation structure [14]. All model fittings were implemented using SAS PROC MIXED and the model with the smallest AIC was considered the best fit [15].

Univariate associations were performed to assess the best functional form of the variables. Continuous variables were assessed as linear and curve-linear with the addition of quadratic terms. Using a hierarchical model building process, clusters of variables were added in, one-by-one. All models included baseline A1C and time (in months) since these two variables were considered essential to control for in assessing glycemic control in the longitudinal format. In each model, the AIC of the best-fitted correlation structure was noted. 
Table I: Population characteristics and univariate associations of factors with mean AIC. Project Dulce, 2000-2002 (N = 573)

\begin{tabular}{|c|c|c|c|}
\hline & n (\%) & Mean AIC (\%) & $P$ value \\
\hline \multicolumn{4}{|l|}{ Demographic factors } \\
\hline Gender, n (\%) & & & 0.99 \\
\hline I. Female & $392(68.7 \%)$ & 7.63 & \\
\hline 2. Male & 179 (31.4\%) & 7.63 & \\
\hline Age, n (\%) & Mean $=55.4 \pm 10.1$ & & $<0.0001$ \\
\hline I. $<50$ years & 149 (26.0\%) & 7.89 & I $>2,3$ \\
\hline 2. $50-65$ & $355(62.0 \%)$ & 7.57 & \\
\hline 3. $>65$ & $69(12.0 \%)$ & 7.36 & \\
\hline Ethnicity, n (\%) & & & $<0.0001$ \\
\hline I. Hispanic & 304 (53.3\%) & 7.84 & $2>3,4$ \\
\hline 2. Black & $39(6.8 \%)$ & 7.96 & $4<2$ \\
\hline 3. Asian & $100(17.5 \%)$ & 7.06 & $3<1,2,5$ \\
\hline 4. Other & $11(1.9 \%)$ & 7.46 & \\
\hline 5. White & $116(20.4 \%)$ & 7.55 & \\
\hline Primary Language, n (\%) & & & 0.18 \\
\hline I. Not English & $302(52.8 \%)$ & 7.58 & \\
\hline 2. English & $270(47.2 \%)$ & 7.68 & \\
\hline \multicolumn{4}{|l|}{ Diabetes severity } \\
\hline Diabetes duration, n (\%) & Mean $=7.1 \pm 7.1$ & & $<0.0001$ \\
\hline I. $<$ I year & $122(21.9 \%)$ & 7.04 & $4>3>2>1$ \\
\hline 2. I - 5 years & 195 (34.9\%) & 7.45 & \\
\hline $3.6-10$ years & $93(16.7 \%)$ & 7.77 & \\
\hline 4. $>10$ years & $148(26.5 \%)$ & 8.19 & \\
\hline Medicine, n (\%) & & & $<0.0001$ \\
\hline I. Insulin alone or insulin + oral agents & 177 (30.9\%) & 8.32 & $1>2>3$ \\
\hline 2. > I oral agent (no insulin) & $284(49.6 \%)$ & 7.58 & \\
\hline 3. No medicine or I oral agent & 112 (19.5\%) & 6.47 & \\
\hline \multicolumn{4}{|l|}{ Health status } \\
\hline Systolic blood pressure, n (\%) & Mean $=125.2 \pm 11.9$ & & 0.33 \\
\hline I. $<130 \mathrm{~mm} \mathrm{Hg}$ & $404(70.5 \%)$ & 7.65 & \\
\hline 2. $\geq 130 \mathrm{~mm} \mathrm{Hg}$ & $169(29.5 \%)$ & 7.57 & \\
\hline Diastolic blood pressure, n (\%) & Mean $=72.1 \pm 6.6$ & & 0.19 \\
\hline I. $<80 \mathrm{~mm} \mathrm{Hg}$ & $506(88.3 \%)$ & 7.64 & \\
\hline 2. $\geq 80 \mathrm{~mm} \mathrm{Hg}$ & $67(11.7 \%)$ & 7.48 & \\
\hline Total cholesterol, n (\%) & Mean $=187.6 \pm 36.0$ & & $<0.0001$ \\
\hline I. $<200 \mathrm{mg} / \mathrm{dl}$ & $386(68.2 \%)$ & 7.45 & \\
\hline 2. $\geq 200 \mathrm{mg} / \mathrm{dl}$ & $180(31.8 \%)$ & 8.03 & \\
\hline HDL, n (\%) & Mean $=45.3 \pm 12.0$ & & 0.27 \\
\hline I. $\leq 45 \mathrm{mg} / \mathrm{dl}$ & $322(56.6 \%)$ & 7.73 & \\
\hline 2. $>45 \mathrm{mg} / \mathrm{dl}$ & 247 (43.4\%) & 7.59 & \\
\hline Urine Microalbumin / creatinine, $\mathrm{n}(\%)$ & Mean $=139.9 \pm 480.7$ & & $<0.0001$ \\
\hline I. $<30 \mathrm{ug} / \mathrm{mg}$ & $356(63.6 \%)$ & 7.40 & $3>2>1$ \\
\hline 2. $30-299 \mathrm{ug} / \mathrm{mg}$ & $160(28.6 \%)$ & 7.84 & \\
\hline 3. $\geq 300 \mathrm{ug} / \mathrm{mg}$ & $44(7.8 \%)$ & 8.55 & \\
\hline Body Mass Index, n (\%) & Mean $=32.5 \pm 7.5$ & & 0.003 \\
\hline I. $<30 \mathrm{~kg} / \mathrm{m}^{2}$ & $246(43.2 \%)$ & 7.50 & \\
\hline 2. $\geq 30 \mathrm{~kg} / \mathrm{m}^{2}$ & $323(56.8 \%)$ & 7.72 & \\
\hline
\end{tabular}


Table I: Population characteristics and univariate associations of factors with mean A I C. Project Dulce, 2000-2002 (N = 573)

\begin{tabular}{|c|c|c|c|}
\hline \multicolumn{4}{|l|}{ Access/quality of care } \\
\hline Insurance, $\mathrm{n}(\%)$ & & & $<0.0001$ \\
\hline I. Uninsured & $169(29.5 \%)$ & 8.10 & $1>2,3$ \\
\hline 2. County Medical Services & $249(43.5 \%)$ & 7.39 & \\
\hline 3. Insurance & $155(27.0 \%)$ & 7.50 & \\
\hline Number of provider visits, $\mathrm{n}(\%)$ & Mean $=10.2 \pm 4.4$ & & 0.002 \\
\hline I. $3-6$ & I I 8 (20.6\%) & 7.72 & $4>2,3$ \\
\hline $2.7-10$ & $225(39.3 \%)$ & 7.56 & \\
\hline 3. $11-15$ & $166(29.0 \%)$ & 7.51 & \\
\hline 4. $>15$ & $64(11.1 \%)$ & 7.93 & \\
\hline Duration in program, $\mathrm{n}(\%)$ & Mean $=15.7 \pm 5.5$ & & 0.0001 \\
\hline 1. $6-12$ months & $212(37 \%)$ & 7.88 & \\
\hline 2. $>12-24$ months & $361(63 \%)$ & 7.53 & \\
\hline Seen by nutritionist, n (\%) & & & 0.32 \\
\hline I. Yes & 475 (82.9\%) & 7.61 & \\
\hline 2. No & $98(17.1 \%)$ & 7.71 & \\
\hline \multicolumn{4}{|l|}{ Behavioral Factors } \\
\hline Smoking habit, n (\%) & & & 0.29 \\
\hline I. Current & $63(12.5 \%)$ & 7.58 & \\
\hline 2. Past & $162(32.0 \%)$ & 7.60 & \\
\hline 3. Never & $281(55.5 \%)$ & 7.72 & \\
\hline Diabetes Classes Attended, n (\%) & Mean $=1.5 \pm 3.0$ & & 0.002 \\
\hline I. 0 & $358(74.3 \%)$ & 7.60 & $2>1>3$ \\
\hline 2. $1-4$ & $42(8.7 \%)$ & 7.88 & \\
\hline $3.5+$ & $82(17.0 \%)$ & 7.31 & \\
\hline
\end{tabular}

Multiple comparison tests in ANOVA were done with the Duncan function in SAS 8.I

All variables significant in one of the hierarchical models at an alpha level of 0.15 were placed together in a separate model. Finally, a parsimonious mean effects model was created, leaving only variables significant at the alpha level of 0.05 . Variable by time interaction terms were entered into the parsimonious mean effects model in a clustered process. Significant interaction terms at the alpha level of 0.05 were then placed together with the parsimonious model. Once the model variables were finalized, correlation structures for fixed and random effects were verified.

\section{Results}

Table 1 shows the study population characteristics and univariate associations of factors with glycemic control.

\section{a. Demographics}

There were more females $(68.7 \%)$ than males $(31.3 \%)$. The mean age was 55.4 years and the younger group had a higher mean A1C (7.9\%) than the other two age groups. Hispanics represented $53.3 \%$ of the study sample and Asians had lower mean A1C values (7.1\%) than Hispanics $(7.8 \%)$, blacks $(8.0 \%)$, and whites $(7.6 \%)$. The majority of the patients $(52.8 \%)$ used a language other than English as their primary language.

\section{b. Diabetes severity}

The mean duration of diabetes was 7.1 years and increasing duration of disease resulted in progressively higher mean $\mathrm{A} 1 \mathrm{C}$ values. Insulin users comprised $30.9 \%$ of the study population and had higher mean A1C values $(8.3 \%)$ than multiple oral medication users $(7.6 \%)$ and those on one oral agent or no medication (6.5\%).

\section{c. Health status}

Mean systolic and diastolic blood pressures were within ADA target recommendations (less than 130 and $80 \mathrm{~mm}$ $\mathrm{Hg}$, respectively) with $70.5 \%$ and $88.3 \%$ of the study population, respectively, meeting the goals. Mean total cholesterol was $187.6 \mathrm{mg} / \mathrm{dl}$ and those with lower total cholesterol (less than $200 \mathrm{mg} / \mathrm{dl}$ ) had lower mean A1C values $(7.5 \%)$ than those with higher total cholesterol levels $(8.0 \%)$. Patients with clinical albuminuria comprised $7.8 \%$ of the study population and had higher mean A1C values $(8.6 \%)$ than those with microalbuminuria $(7.8 \%)$ and those with no microalbuminuria $(7.4 \%)$. The 
Table 2: Multivariate mixed effects model to assess characteristics associated with glycemic control. Project Dulce, 2000-2002 (N = 555)

\begin{tabular}{|c|c|c|c|}
\hline & Estimate & $P$ value & Translation* \\
\hline Baseline AIC & 0.06050 & $<0.0001$ & \\
\hline Month $(0-24)$ & & $<0.0001$ & \\
\hline Insurance & & 0.003 & \\
\hline Uninsured & 0.02198 & 0.06 & $5.2 \%$ increase in $\mathrm{AIC}$ \\
\hline County Medical Services (MIA) & -0.01300 & 0.20 & \\
\hline Insured (ref) & - & - & \\
\hline Diabetes duration & & $<0.0001$ & \\
\hline$>10$ years & 0.06169 & $<0.0001$ & $15.3 \%$ increase in $\mathrm{AIC}$ \\
\hline $6-10$ years & 0.03555 & 0.008 & $8.5 \%$ increase in $\mathrm{AIC}$ \\
\hline $1-5.9$ years & 0.03253 & 0.003 & $7.8 \%$ increase in $\mathrm{AIC}$ \\
\hline < I year (ref) & - & - & \\
\hline Medicine & & $<0.000$ I & \\
\hline Insulin alone or insulin + oral agents & 0.08768 & $<0.0001$ & $22.4 \%$ increase in $\mathrm{AIC}$ \\
\hline$>$ I oral agent (no insulin) & 0.04930 & $<0.0001$ & $12.0 \%$ increase in $\mathrm{AIC}$ \\
\hline No medicine or I oral agent (ref) & - & - & \\
\hline $\begin{array}{l}\text { Total cholesterol }(0.65 \mathrm{mmol} / \mathrm{l}(25 \mathrm{mg} / \mathrm{dl}) \\
\text { interval) }\end{array}$ & 0.01115 & $<0.001$ & $2.6 \%$ increase in $\mathrm{AIC}$ \\
\hline Age $*$ month & & $<0.001$ & \\
\hline
\end{tabular}

* Formula for calculating change in $\mathrm{AIC}=10$ (estimate) $-\mathrm{I}$

$10(0.02198)-1=0.052$

majority (56.8\%) of the patients were obese and they had higher mean A1C values (7.7\%) than those who were not obese $(7.5 \%)$.

\section{d. Access / quality of care}

The largest (43.5\%) group of patients were enrolled in San Diego County Medical Services followed by the uninsured (29.5\%). Uninsured patients had higher mean A1C values $(8.1 \%)$ than those with insurance $(7.5 \%)$ or County Medical Services (7.4\%). Most (63.0\%) of the study patients were enrolled in Project Dulce over one year and this group had lower mean A1C values (7.5\%) compared to the group enrolled for one year or less (7.9\%). Patients with greater than 15 provider visits had higher mean A1C values $(7.9 \%)$ than those with less provider visits. The majority $(82.9 \%)$ of the patients had seen a Project Dulce nutritionist.

\section{e. Behavioral factors}

Current smokers comprised $12.5 \%$ of the study population. Patients who attended 5 or more Project Dulce diabetes classes had lower (7.3) mean A1C values than those who attended no classes (7.6) and those attending 1 to 4 classes (7.9).

Table 2 provides the regression results for the multivariate mixed effects model analysis which illustrates the factors associated with glycemic control. Insurance status, disease duration, pharmacotherapy, and cholesterol level were significantly associated with glucose control. Fluctuation in mean A1C over time also differed by age (age* month). Using the insured as the reference group, the uninsured had a 5.2\% higher A1C level. Patients who had diabetes over ten years had a $15.3 \%$ higher A1C level compared to those who had diabetes less than one year. Similarly, patients who had diabetes six to ten years and one to five years had significantly higher A1C values compared to those with diabetes less than one year. Patients who required insulin had a $22.4 \%$ higher $\mathrm{A} 1 \mathrm{C}$ and those who required more than one oral medication had a $12.0 \%$ higher A1C compared to hose who used one oral medication or no medication at all. On average, for every 0.65 $\mathrm{mmol} / \mathrm{l}(25 \mathrm{mg} / \mathrm{dl})$ increase in total cholesterol, the A1C value was $2.6 \%$ higher.

How mean A1C fluctuated over time differently for various age groups is best interpreted with a plot. Although age was a continuous variable in this analysis, for purposes of interpretation, we created three categories. Figure 1 demonstrates that the less than 50 years of age group initially declined in $\mathrm{A} 1 \mathrm{C}$ from baseline to three months but then slowly rose during the next fifteen months. The two older age groups had lower mean A1C values that fluctuated during those fifteen months.

\section{Conclusion}

Univariate analysis indicates that multiple variables are associated with glycemic control. Age, race/ethnicity, disease duration, medication, number of Project Dulce visits, duration in Project Dulce, total cholesterol, 


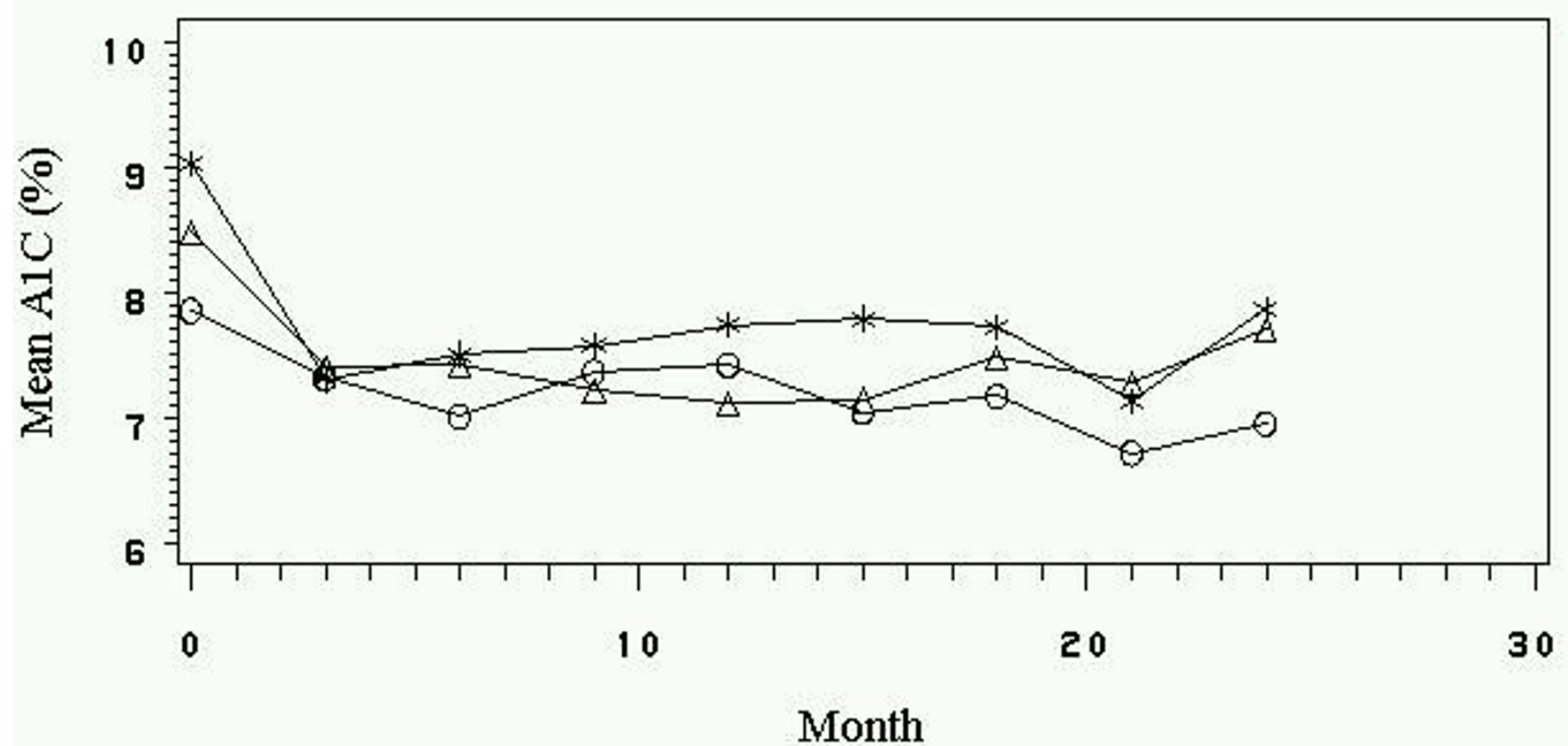

\section{Age Group $* * *<50$ years $\triangle \Delta \triangle 50-65$ years $\theta 0 \theta>65$ years}

\section{Figure I}

Fluctuation in mean AIC values over time by age group. Project Dulce, 2000-2002

microalbumin-to-creatinine ratio, BMI, insurance status, and the number of diabetes classes attended were all significant. However, after controlling for baseline A1C, time and other demographic, disease severity, health status, and access/quality of care factors, only age, insurance status, disease duration, pharmacotherapy, and total cholesterol were significant in the final model with main effects or two-way interaction terms.

The association of insurance status with glycemic control contradicts previous studies. Harris et al. [9] did not find an association between glycemic control and insurance coverage or socioeconomic status using NHANES III data, a representative sample of the U.S. population. Similarly, the Michigan community study [12], a study of blacks and whites in South Carolina [16], and a study of whites and Mexican-Americans in Texas [17] did not find an association between glycemic control and socioeconomic status. Our population, however, is distinct. It is a multiracial/ ethnic population and all have a low socioeconomic status. Within this low-income population, the uninsured had poorer glycemic control. They represent a subgroup of patients that struggle to find care for a disease that requires close monitoring. Their disease state may have been out-of-control before entering Project Dulce and thus more difficult to gain control. They may also have lacked self-care skills or basic knowledge of diabetes since their care in the past was likely sporadic. Perhaps, factors such as dietary practices, physical exercise, and education level were important predictors and differed in this subgroup $[18,19]$. Providers may have difficulty procuring medication and equipment for this group of patients. All of these factors could help explain the discrepancy but were not accounted for in this study.

Study findings have differed on the association of glycemic control and disease duration. Similar to Blaum et al. [12] and contradictory to Nichols et al. [11], we found that the longer someone had been diagnosed with diabetes, the harder it was to maintain glycemic control. Although self-care skills could improve with longer duration of disease, resistance to medication and the need for higher doses or additional medications increase over time. Insulin use is also a factor of disease severity and was 
a predictor of poorer glycemic control in this study. The mean A1C value (8.3\%) of insulin users in our study was equivalent to the mean value of insulin users in the NHANES III data [9]. They also found insulin users to have poorer glucose control.

Among health status factors, high total cholesterol was associated with poorer glycemic control. Since patients with diabetes are already at high risk for cardiovascular disease, this finding reinforces the need to aggressively screen and treat elevated cholesterol.

Although other health status factors were not associated with glycemic control in multivariate analysis, it is important to assess the health status of Project Dulce patients compared to other populations. Harris [20] studied health status and outcomes using NHANES III. Blood pressure was elevated (greater than or equal to $140 / 90$ $\mathrm{mm} \mathrm{Hg}$ ) in $55 \%$ to $65 \%$ of the population compared to Project Dulce's 30\% for SBP (greater than $130 \mathrm{~mm} \mathrm{Hg}$ ) and $12 \%$ for DBP (greater than $80 \mathrm{~mm} \mathrm{Hg}$ ). Total cholesterol was greater than or equal to $200 \mathrm{mg} / \mathrm{dl}$ in $62 \%$ to $69 \%$ of the NHANES III population compared to $32 \%$ of the Project Dulce population. Cigarette smokers compreised $18 \%$ to $24 \%$ of NHANES III and $13 \%$ of Project Dulce. The prevalence of microalbuminuria and obesity, however, was higher in the Project Dulce population than NHANES III, $36.4 \%$ vs. $26 \%$ to $30 \%$ and $57 \%$ vs. $34 \%$ to $54 \%$, respectively. The fact that a higher proportion of Project Dulce patients compared to a representative sample of the U.S. population were meeting ADA blood pressure and cholesterol recommendations suggests the positive impact and importance of community disease management programs in low-income, multiracial/ethnic communities.

Prior studies have demonstrated race/ethnicity as a predictor of glycemic control with higher proportions of poorly controlled patients among black women and MexicanAmerican men [9]. In univariate analysis, our study found that Asians had better glycemic control than Hispanics, blacks, and whites. However, this relationship disappeared in multivariate analysis after taking other factors into account. Perhaps the reason why our finding differs from other studies is that regardless of race/ethnicity, all study patients were of low socioeconomic status. Prior studies examined race/ethnicity in populations with differing socioeconomic status levels.

Similar to results from Shorr et al.'s study [10] using NHANES III data, our study found that in multivariate analysis, age was not a significant main effect in predicting glucose control. However, the significant age by time interaction term (age* month) indicates that A1C patterns over time differed between age groups. Figure 1 shows that while the 50 to 65 and 65 and over age groups' A1C values fluctuated over time, the younger age group's $\mathrm{A} 1 \mathrm{C}$ values steadily rose. Nichols et al. [11] also found poorer metabolic control among the younger age group. Since our longitudinal analysis accounted for fluctuations in A1C values, we were able to study A1C pattern differences. It would be interesting to see if this same A1C pattern difference among age groups exists in a representative sample of the U.S. population.

The strength of the current study was the use of mixed effects models. This is the first study that used a longitudinal approach to find factors associated with glycemic control. Incorporating repeated measures over time accounts for fluctuations in glucose control and maximizes the amount of information that can be drawn from the data. Another advantage was the size and diversity of the population which included large numbers of Hispanic, Asian, and white patients, far more diverse than studies using representative samples of the U.S. population.

While the race/ethnic population was diverse, the socioeconomic status of the population was not. Most of the patients were of very low income which limits the generalizability of the study results. Missing data was also a limitation. Missing quarterly A1C values was common but mixed effects models still yield unbiased estimates provided that the missing data was missing at random (MAR) [14].

Finally, multiple factors affect glycemic control. The mixed effects model incorporated demographic, disease severity, health status, access/quality of care, and behavioral factors but these are just some of the possible factors that affect glycemic control. Psychological and biological factors, self-care skills, knowledge of disease and education level, diet, exercise, other comorbid diseases, etc. were not explained by this model. Nichols et al.'s [11] study found that only $9 \%$ of the variability in glycemic control was explained by the factors in their model and suggested that personal characteristics may not explain a lot of differences in glycemic control among patients with Type 2 diabetes.

This study identified patients with poorer glycemic control in Project Dulce. The findings should not be generalized to all patients with Type 2 diabetes but can be applied to racial/ethnically diverse, low-income populations. Those who were uninsured, had diabetes for a longer period of time, used insulin or multiple oral agents, or had high cholesterol had poorer glycemic control. The younger population also lagged behind others. Secondarily, this study showed that a high proportion of the patients were meeting ADA's blood pressure and cholesterol recommendations, suggesting that community 
disease management programs in low-income populations can be effective and may contribute to improved health outcomes.

This study provides a useful methodology to assess disease management systems that collect longitudinal data. It does not provide answers to why patients are not optimally controlled but does provide a starting point from which to investigate and address the obstacles that prevent patients with diabetes from reaching their metabolic targets.

\section{Competing interests}

The author(s) declare that they have no competing interests.

\section{Authors' contributions}

SB designed and wrote the study and analyzed the data. MJ participated with the design, analysis and interpretation of the data and revision of the paper. RF participated in the design and writing of the paper. AT acquired the data and participated in the design and revision of the paper. All authors read and approved the final manuscript.

\section{References}

I. National Institute of Diabetes and Digestive and Kidney Diseases: National Diabetes Statistics fact sheet: general information and national estimates on diabetes in the United States, 2003. Bethesda, MD: U.S. Department of Health and Human Services, National Institutes of Health, 2003. Rev. ed. Bethesda, MD: U.S. Department of Health and Human Services, National Institutes of Health 2004 [http://diabetes.niddk.nih.gov/dm/pubs/statistics/index.htm\#7]. Accessed February 5, 2005.

2. Bishop DB, Zimmerman BR, Roesler JS: Diabetes. In Chronic Disease Epidemiology and Control 2nd edition. Edited by: Brownson RC, Remington PL, Davis JR. Washington, DC: The American Public Health Association; 1998:42I-464.

3. Arias E, Smith BL: Deaths: preliminary data for 200I. In National vital statistics reports Volume 5I. Issue 5 Hyattsville, MD: National Center for Health Statistics; 2003.

4. Dept of Health and Human Services (US): Health people 2010: Understanding and improving health 2nd edition. Washington, DC: US Government Printing Office; 2000.

5. U.K. Prospective Diabetes Study Group: Intensive blood-glucose control with sulphonylureas or insulin compared with conventional treatment and risk of complications in patients with type 2 diabetes (UKPDS 33). Lancet 1998, 352:837-853.

6. Ohkubo $\mathrm{Y}$, Kishikawa H, Araki E, Miyata T, Isami S, Motoyoshi S, Kojima Y, Furuyoshi N, Shichiri M: Intensive insulin therapy prevents the progression of diabetic microvascular complications in japanese patients with non-insulin-dependent diabetes mellitus: a randomized prospective 6-year study. Diabetes Res Clin Pract 1995, 28: 103-1 17.

7. American Diabetes Association: Standards of medical care for patients with diabetes mellitus. Diabetes Care 2003, 26:33-50.

8. Norris SL, Nichols PJ, Caspersen CJ, Glasgow RE, Engelgau MM, Jack L, Isham G, Snyder SR, Carande-Kulis VG, Garfield S, Briss P, McCulloch $D$ : The effectiveness of disease and case management for people with diabetes. Am J Prev Med 2002, 22:15-38.

9. Harris MI, Eastman RC, Cowie CC, Flegal KM, Eberhardt MS: Racial and ethnic differences in glycemic control of adults with type 2 diabetes. Diabetes Care 1999, 22:403-408.

10. Shorr RI, Franse LV, Resnick HE, Di Bari M, Johnson KC, Pahor M: Glycemic control of older adults with type 2 diabetes: Find- ings from the Third National Health and Nutrition Examination Survey, 1988-1994. J Am Geriatr Soc 2000, 48:264-267.

II. Nichols GA, Hillier TA, Javor K, Brown JB: Predictors of glycemic control in insulin-using adults with type 2 diabetes. Diabetes Care 2000, 23:273-277.

12. Blaum CS, Velez L, Hiss RG, Halter JB: Characteristics related to poor glycemic control in niddm patients in community practice. Diabetes Care 1997, 20:7-II.

13. Philis-Tsimikas A, Walker C: Improved care for diabetes in underserved populations. J Ambulatory Care Management 200I, 24:39-43.

14. Verbeke G, Molenberghs G: Linear mixed models for longitudinal data New York: Springer; 2000.

15. Ngo L, Brand R: Model selection in linear mixed effects models using sas proc mixed: Technical proceedings. SAS Users Group International 1997, 22: I-6.

16. Eberhardt MS, Lackland DT, Wheeler FC, German RR, Teutsch SM: Is race related to glycemic control? An assessment of glycosylated hemoglobin in two South Carolina communities. J Clin Epidemiol 1994, 47: I I8I-I I89.

17. Haffner SM, Hazuda HP, Stern MP, Patterson JK, Van Heuven WAJ, Fong $D$ : Effect of socioeconomic status on hyperglycemia and retinopathy levels in Mexican Americans with NIDDM. Diabetes Care 1989, I 2: 128-134.

18. Schillinger D, Grumbach K, Piette J, Wang F, Osmond D, Daher C, Palacios J, Sullivan GD, Bindman AB: Association of health literacy with diabetes outcomes. JAMA 2002, 288:475-482.

19. Goldman DP, Smith JP: Can patient self-management help explain the SES health gradient? PNAS 2002, 99: 10929-10934.

20. Harris MI: Racial and ethnic differences in health care access and health outcomes for adults with type 2 diabetes. Diabetes Care 200I, 24:454-459.

\section{Pre-publication history}

The pre-publication history for this paper can be accessed here:

http://www.biomedcentral.com/1471-2458/5/36/prepub

Publish with Bio Med Central and every scientist can read your work free of charge

"BioMed Central will be the most significant development for disseminating the results of biomedical research in our lifetime. "

Sir Paul Nurse, Cancer Research UK

Your research papers will be:

- available free of charge to the entire biomedical community

- peer reviewed and published immediately upon acceptance

- cited in PubMed and archived on PubMed Central

- yours - you keep the copyright 